\title{
Apropriação da análise de discurso crítica em uma discussão sobre comunicação social
}

\section{Appropriation of critical discourse analysis in a discussion about media}

\author{
Viviane de Melo Resende \\ Universidade de Brasília (UnB), Brasília, DF / Brasil \\ $\mathrm{CNPq}$ \\ resende.v.melo@gmail.com \\ María del Pilar Tobar Acosta \\ Instituto Federal de Brasília (IFB), Brasília, DF / Brasil \\ UnB \\ acosta.pilar@gmail.com
}

Resumo: Com o intuito de entender a forma como os street papers representam a situação de rua e em que medida oferecem espaço para pessoas nessa situação se autorrepresentarem, realizou-se uma pesquisa qualitativa em que foram analisados cinco jornais e revistas publicados no Brasil e em Portugal. Para este artigo, foi composto um corpus documental formado por cinco volumes consecutivos do jornal $O$ Trecheiro. Com base na Análise de Discurso Crítica, este trabalho investiga a maneira como se deu a representação da situação de rua nesses volumes do periódico, explorando as seguintes categorias analíticas: significado de palavra, intertextualidade, representação de atores sociais e interdiscursividade. A inclusão, nos textos do jornal, de vozes de pessoas nessa condição abre espaço para sua autorrepresentação, o que possibilita a materialização de narrativas outras, por outros prismas experienciais. Nesse espaço, leitores/ as em situação de rua, público preferencial dessa iniciativa, podem se ver 
representados/as, podem construir modos alternativos de identificação, com base em outros modos particulares de representação (discursos), para muito além daqueles que os/as desumanizam.

Palavras-chave: análise de discurso crítica; publicações de rua; situação de rua.

Abstract: In order to understand how street papers represent homelessness and to what extent provide space for homeless people self-represention, a qualitative research investigating five newspapers and magazines published in Brazil and Portugal was held. For this paper, we composed a corpus of five consecutive volumes of the newspaper $O$ Trecheiro. Based on Critical Discourse Analysis, we investigate the representation of homelessness in these volumes of the journal, exploring the analytical categories lexicon, intertextuality, representation of social actors and interdiscursivity. The inclusion of voices of people in homelessness in the texts of the newspaper opens space for their self-representation, which allows the materialization of other narratives, by other experiential prisms. In this space, homeless readers can see themselves represented; they can construct alternative modes of identification, based on other particular modes of representation (discourses), far beyond those which dehumanize them.

Keywords: critical discourse analysis; street papers; homelessness.

Recebido em 17 de fevereiro de 2017.

Aprovado em 13 de fevereiro de 2017.

\section{Introdução}

A rua é o lugar comum por excelência; quem nela vive fica exposto/a o tempo todo ao contato com os/as demais. Contudo, nem sempre uma pessoa em situação de rua convive com os/as que passam. Apesar da apartação social (BUARQUE, 2003), ou mesmo em razão dela, emergem mobilizações que acabam se tornando recurso para a construção identitária, criando assim um lugar simbólico. É o caso de publicações voltadas para a situação de rua, os chamados street papers, alguns dos quais se articulam em uma rede internacional, a International Network of Street Papers (INSP). 
Com o intuito de entender como alguns desses jornaisespecificamente aqueles produzidos em língua portuguesa e integrados à INSP - representam a situação de rua e em que medida oferecem espaço para pessoas em situação de rua se autorrepresentarem, foi realizada uma pesquisa qualitativa entre 2010 e 2014 , em projeto de pesquisa integrado que articulou cinco projetos particulares. O projeto integrado, coordenado por Viviane de Melo Resende, articulou os projetos de Acosta (2012), Santos, A. (2013), Santos, G. (2013) e Resende (2011), investigando cinco jornais e revistas publicados no Brasil e em Portugal e ligados à INSP. Realizado no Programa de Pós-Graduação em Linguística e vinculado ao Núcleo de Estudos de Linguagem e Sociedade (NELiS) da Universidade de Brasília, o projeto foi apoiado pela Fundação de Apoio à Pesquisa do Distrito Federal e premiado pelo Centro de Estudos Sociais da Universidade de Coimbra, Portugal.

Neste artigo, a fim de ilustrar como a Análise de Discurso Crítica pode ser apropriada em um projeto particular, concentramo-nos em apresentar alguns dos resultados de pesquisa pertinentes a apenas uma das publicações estudadas: o jornal $O$ Trecheiro, produzido em São Paulo pela Rede Rua de Comunicação $(<\mathrm{http}: / /$ www.rederua.org. $\mathrm{br} /$ rederua/ $>$ ). Foi composto um corpus documental formado por cinco volumes consecutivos do jornal - agosto de 2010, setembro/outubro de 2010 , novembro de 2010, dezembro de 2010 e janeiro/fevereiro de 2011. Com base em arcabouço teórico-metodológico oferecido em Análise de Discurso Crítica (FAIRCLOUGH, 2001; FAIRCLOUGH, 2003; FAIRCLOUGH, 2010; RAMALHO; RESENDE, 2011; VIEIRA; RESENDE, 2016; PARDO ABRIL, 2008), procuramos investigar, por meio de análise textualmente orientada, a maneira como se deu a representação da situação de rua nesses volumes do periódico. Para a análise dos textos, exploramos as seguintes categorias analíticas: significado de palavra, tendo como foco a oposição desse jornal às práticas jornalísticas tradicionais; intertextualidade e representação de atores sociais, observando em que medida pessoas em situação de rua, de fato, participam dos/nos textos; e interdiscursividade, investigando quais discursos estão mais presentes nos textos, como aparecem e como são articulados.

O artigo organiza-se em três seções. Na primeira, oferecemos um breve panorama sobre jornais de rua, observando as especificidades do jornal $O$ Trecheiro. Na segunda, traçamos uma revisão teórica 
em Análise de Discurso Crítica, do arcabouço teórico-prático cuja apropriação intentamos exemplificar. A terceira seção dedica-se às análises discursivas, divididas em três subseções. Apresentamos por fim algumas considerações sobre o trabalho realizado.

\section{Jornais de rua - o caso específico de $\boldsymbol{O}$ Trecheiro}

Os jornais de rua (street papers) constituem um suporte alternativo para a veiculação de informações sobre temas relativos à situação de rua, ao mesmo tempo que possibilitam um trabalho alternativo na venda das publicações. Esse tipo de publicação foi inicialmente realizado em Londres pela revista pioneira The Big Issue, em 1991. Atualmente existem mais de 100 street papers, distribuídos em 35 países e publicados em 24 línguas, nos seis continentes, reunidos em uma associação internacional, a International Network of Street Papers (INSP). Conforme a associação, esses periódicos pretendem constituir "uma só voz contra a pobreza" (INSP).

O principal objetivo dessas publicações é a possibilidade de geração de renda para pessoas que foram marginalizadas pelo sistema econômico, buscando a superação de algumas das consequências nefastas da acumulação de capital. À diferença de outros periódicos destinados à população em situação de rua, $O$ Trecheiro não tem o objetivo de ser uma ferramenta econômica, tendo em vista que sua distribuição é gratuita. Assim, $O$ Trecheiro não atende a uma diretriz básica do funcionamento de jornais de rua configurados como street papers: a geração de renda. Todos os demais jornais e revistas de rua investigados no projeto integrado que mencionamos na Introdução (Aurora da Rua, Boca de Rua, Cais e Ocas), de que este artigo é recorte, são ferramentas para geração de renda e alternativas de trabalho informal, já que são vendidos nas ruas por pessoas em situação de rua, para as quais é revertida uma parcela da receita das vendas. No caso de $O$ Trecheiro, por outro lado, trata-se de jornal de distribuição gratuita, que se constitui um veículo de comunicação de questões especificamente relacionadas à situação de rua, às mobilizações sociais referentes ao tema, às políticas públicas específicas, às lutas e conquistas nesse campo.

O jornal é uma das ações da Rede Rua de Comunicação (2011), como consta em seu site: 
Desde os anos de 1980, a Rede Rua promove comunicação a partir dos excluídos. Documenta e assessora a comunicação de movimentos, entidades e grupos sociais e populares.

Jornal "O Trecheiro" - Há 15 anos publica a realidade do povo de rua e registra a história de luta e de esperança do povo excluído. ${ }^{1}$

Produção de Vídeos - Produz vídeos socioeducativos e documentários, acompanhando a organização dos grupos populares.

Fotografia - Registra fatos e manifestações de interesse social, principalmente, da população em situação de rua. Videoteca - Dispõe de 900 títulos que retratam experiências de inclusão social: organização, formação política, humana e religiosa.

A entidade pretende, dessa maneira, documentar e assessorar "a comunicação de movimentos, entidades e grupos sociais e populares" (Rede Rua de Comunicação), por meio de fotografias, vídeos e textos, tendo como objetivo atuar sobre o processo de exclusão social (ACOSTA; RESENDE, 2014b). Alderón Costa, diretor da Rede Rua e editor chefe de $O$ Trecheiro até 2014, é também fundador da revista Ocas, que segue a fórmula dos jornais de rua. Assim, $O$ Trecheiro é, provavelmente, uma ação complementar, dentro desse esforço por maior visibilidade às demandas da população em situação de rua (ACOSTA, 2012).

Quanto à estrutura física, podemos dizer que o periódico, composto por uma folha jornal que, dobrada, resulta em quatro páginas, apresenta semelhanças com os jornais de grande circulação, no que tange a sua organização. É um suporte impresso, no qual é possível ler textos que materializam gêneros tradicionais do jornalismo - editorial, colunas de opinião, reportagens, entrevistas, entre outros -, sendo esses textos escritos no formato canônico de narrativa jornalística. Desse modo, como verificado em trabalho anterior, "O Trecheiro atende à expectativa gerada pelo suporte jornal. As notícias são acompanhadas, na maioria dos casos, de imagens que ilustram a informação presente nos textos verbais, o que também é uma característica convencional para o suporte" (ACOSTA; RESENDE, 2014b, p. 153).

\footnotetext{
${ }^{1}$ Em 2015, O Trecheiro comemorou os 20 anos de sua criação.
} 
$O$ Trecheiro focaliza questões relativas à situação de rua: todas as informações e notícias veiculadas orbitam essa temática. O jornal já publicou, por exemplo, estudos sobre o trabalho de pessoas em situação de rua, reproduções de trechos de cartilhas, reflexões sobre a Política Nacional para Inclusão da População em Situação de Rua, entre muitos outros textos abordando diversos assuntos, mas sempre com o foco na rua. Pela forma como é feito e distribuído, acreditamos que $O$ Trecheiro é um instrumento de resistência social extremamente relevante na luta pela valorização de pessoas que se encontram em situação de vulnerabilidade. Esperamos que este artigo possa ilustrar por quê.

\section{Análise de Discurso Crítica como teoria e método para refletir sobre questões sociais}

A Análise de Discurso Crítica (ADC) inscreve-se na linguística funcionalista e baseia-se fundamentalmente na ideia de que a linguagem funciona na sociedade, sendo por ela modificada e podendo, dialeticamente, provocar mudanças sociais. Por essa razão, seu desenvolvimento exigiu contribuições de outros estudos para viabilizar uma análise social e linguística, assim estabelecendo interfaces com diferentes áreas do conhecimento. Desse modo, a ADC constitui-se uma interdisciplina que oferece um rico quadro teórico-metodológico para investigar a linguagem em sociedade, com base na análise situada de textos.

Para lograr construir crítica explanatória (conceito de BHASKAR, 1998; veja também FAIRCLOUGH; JESSOP; SAYER, 2002), todo estudo em ADC precisa se apoiar em conceitos cuidadosamente discutidos e aplicados, o que possibilita o rigor analítico necessário para se produzirem pesquisas relevantes. Nesta seção, apresentamos uma breve revisão teórica, pautando-nos por conceitos centrais à prática de pesquisa em ADC. Em nossa revisão, focalizamos versões de ADC desdobradas do trabalho de Norman Fairclough e seus desenvolvimentos na América Latina.

\subsection{Linguagem e sociedade - a sofisticação das tecnologias de texto}

Para a ADC, a instância discursiva é parte indissociável da vida social, estando interconectada com outras - crenças, valores, ideologias, atividade material, relações sociais, instituições, posições. É um 'momento' da prática social passível de ser analisado em função da materialidade dos 
textos produzidos em eventos sociais (CHOULIARAKI; FAIRCLOUGH, 1999). Qualquer ato comunicativo constitui texto, estando compreendidos desde textos escritos - textos de jornais, livros, publicidade, entre muitos outros - ou textos orais - conversas, aulas, programas de televisão, entre muitos outros - até textos multimodais, que se utilizam de diferentes modalidades de linguagem (verbal escrita, verbal oral, imagética estática, imagética dinâmica, musical etc.) em sua composição. Isso significa dizer que outras semioses, para além da linguagem verbal, são incluídas no conceito ampliado de texto e são passíveis de análise. No caso de imagens, por exemplo, temos textos imagéticos que podem ser analisados, entre outros enquadres, pelo arcabouço da Gramática do Design Visual (KRESS; van LEEUWEN, 1996) ou pelos Estudos Críticos do Discurso Multimodal (PARDO ABRIL, 2011), ou ainda, no caso de filmes, por exemplo, pelo Método de Análise de Discurso Audiovisual, segundo D’Angelo (2012).

Textos de quaisquer tipos e materializados em quaisquer gêneros são entendidos como eventos discursivos situados na medida em que existem pela/na linguagem e, ao mesmo tempo, articulam diferentes discursos, uma vez que materializam determinadas formas de ver o mundo ou parte dele. Disso depreende-se uma dupla acepção para 'discurso', desenvolvida nos trabalhos de Norman Fairclough: como substantivo abstrato, significa "linguagem como momento irredutível da vida social" e, como substantivo contável, significa um "modo particular de representar parte do mundo", ligado a interesses específicos (VIEIRA; RESENDE, 2016, p. 17).

Com base nessa segunda acepção, sinaliza-se o estabelecimento de redes de ordens de discurso, nas quais as ações discursivas são possibilitadas e reguladas. ${ }^{2}$ As ordens de discurso são, assim como as práticas, no que se refere à relação entre estruturas sociais e a agência humana, o ponto de conexão entre o sistema abstrato (mecanismos e estruturas linguísticas) e a realização concreta (textos). Nessa perspectiva, diferentes discursos, sendo diferentes formas de significar o mundo, estão

\footnotetext{
${ }^{2}$ Ordens de discurso são "as combinações particulares de gêneros, discursos e estilos que constituem o aspecto discursivo de redes de práticas sociais" (FAIRCLOUGH, 2003 , p. 220), isto é, correspondem à estruturação social da linguagem. O conceito conforme proposto por Chouliaraki e Fairclough (1999) retoma a formulação de Foucault (1999 [1971]).
} 
atrelados a diferentes práticas sociais e são estruturados em função de interesses particulares (FAIRCLOUGH, 2010). Essas práticas devem ser analisadas segundo a percepção de que são frutos de processos sociais e que na mesma medida os reproduzem e/ou modificam.

Partindo dos estudos da gramática funcional de Halliday (1985), houve em ADC a operacionalização das metafunções da linguagem propostas pelo linguista - ideacional, interpessoal e textual - em três significados da linguagem - representacional, acional e identificacional (FAIRCLOUGH, 2003). Essa recontextualização teórica da multifuncionalidade da linguagem enfatiza que, por meio de textos, atores sociais representam o mundo, agem sobre ele e identificam(-se). Assim, para ADC, qualquer evento discursivo (resultando texto) articula diferentes significados. Esses significados são mais característicos de determinadas instâncias dos textos, como, por exemplo, os discursos presentes nos textos que dão a ver a forma como o mundo está sendo representado. Há, dessa maneira, uma correspondência entre o significado representacional e os discursos (FAIRCLOUGH, 2003). No mesmo sentido, o significado acional articula-se aos gêneros textuais, e o significado identificacional, aos estilos. Para acessar esses diferentes significados nos textos, foram desenvolvidas categorias analíticas, que "são formas e significados textuais associados a maneiras particulares de representar, de (inter)agir e de identificar(-se) em práticas sociais situadas" (VIEIRA; RESENDE, 2016, p. 112).

Em ADC, devemos enfatizar, teoria (do funcionamento social da linguagem) e método (de análise discursiva) são importantes e andam juntos. Esse aspecto dos estudos discursivos críticos e sua relevância para a capacidade explanatória de pesquisas discursivas têm sido destacados nos desenvolvimentos da ADC na América Latina (PARDO, 2011; RESENDE, no prelo). Os procedimentos metodológicos, destacado o trabalho com categorias linguísticas, estão atrelados à instância de conceitos sociológicos, o que reflete o caráter teórico-metodológico da área. Assim, para viabilizar a análise social textualmente orientada, categorias analíticas desenvolvidas na linguística funcional, em suas diversas vertentes, são articuladas em ADC, objetivando acessar a instância das práticas sociais nos usos da linguagem. Desse modo, é possível mapear as conexões entre o discursivo e o não discursivo, tendo em vista seus efeitos sociais. 
Outro imperativo para o/a analista em ADC é procurar compreender em profundidade a conjuntura social, para uma efetiva investigação das práticas sociais em seu aparato discursivo. Em ADC, o atual momento de desenvolvimento da sociedade é entendido como "novo capitalismo" (FAIRCLOUGH, 2006), expressão que, em contraste com outras formas de se descrever esse mesmo momento histórico - pósmodernidade, modernidade tardia, modernidade fluida/liquida-, enfatiza as consequências das sucessivas reestruturações do sistema econômico para a constituição da sociedade. Essas mudanças do capitalismo são (re) adaptações cujo objetivo central é a perpetuação de práticas capitalistas que, a seu turno, perpetuam a distribuição desigual de poder que esse sistema econômico-social garante. Essas mudanças põem em curso movimentos que se fazem sentir nas mais distintas áreas da vida social (CANCLINI, 2006), e, por isso, o foco no novo capitalismo não se reduz a um foco em questões econômicas (FAIRCLOUGH, 2006).

A linguagem, como parte indissociável da vida social, é afetada por esses movimentos, dos quais se deve ressaltar a tecnologização dos diferentes momentos da vida social, que acarreta a especialização de discursos na sociedade - criando 'feudos simbólicos', em que cada assunto da vida deve ser e só pode ser tratado de forma sistematizada por profissionais específicos de cada área. Isso, levado às últimas consequências, desempodera pessoas que não detêm os recursos necessários para ter acesso a esses conhecimentos (MAGALHÃES, 2000; FAIRCLOUGH, 2008).

Assim, é possível falar em uma tecnologia textual (discursiva), que vem sendo amplamente desenvolvida e explorada pelas mais diversas redes sociais - e aqui não nos referimos apenas à web. Desse modo, é emergente o interesse no conhecimento sobre os usos da linguagem, e cada vez mais a tecnologia é aplicada à produção de textos, com os mais diversificados objetivos. No entanto, deve-se ponderar que aqueles/ as que detêm os meios e os recursos para ter acesso ao conhecimento especializado de construção textual ganham status (ou o mantêm) ao serem capazes de 'distribuir' sua forma de ver o mundo. E, assim, sobrepõem-se às/aos que, em alguma medida, estão desprovidas/os desses meios e recursos, o que incide sobre a perpetuação, pelo uso da linguagem, de assimetrias sociais existentes, em favor de interesses particulares. 
Essa é uma forma - mas não a única - de associação entre linguagem e novo capitalismo. Tendo em vista que textos, como eventos discursivos, estão ligados às práticas sociais, é possível entender os motivos que impulsionaram a sofisticação das tecnologias de texto. Também disso decorre a relevância de se investigarem processos sociais por meio de análise textualmente orientada.

\subsection{Hegemonia e ideologia - a relevância da pesquisa em ADC}

Em ADC, entende-se que estruturas de poder são alvo de lutas também na esfera discursiva. Sobre a noção de hegemonia em Gramsci (1995), Fairclough (2001, p. 85) comenta que "Nessa abordagem, a hegemonia é concebida como um equilíbrio instável construído sobre alianças e geração de consenso das classes ou grupos subordinados, cujas instabilidades são os constantes focos de lutas". A complexidade da noção de poder em ADC também lança mão do pensamento de Foucault, que nos ensina sobre a natureza multifacetada das relações de poder, que não devem ser entendidas como simples linearidades.

Assim, existe a necessidade de a hegemonia dobrar-se sobre si mesma, produzindo sentidos - discursos - que mascaram os mecanismos de poder e de dominação. Para Fairclough (2010), quanto mais opacos parecerem esses modos de operação de sentidos a serviço da manutenção de relações de poder, mais o discurso trabalha na manutenção de sua estabilidade e na consequente perpetuação de relações sociais assimétricas. $\mathrm{O}$ autor ensina que:

O poder é implícito nas práticas sociais cotidianas, que são distribuídas universalmente em cada nível de todos os domínios da vida social e são constantemente empregadas; além disso, o poder 'é tolerável somente na condição de que mascare uma grande parte de si mesmo. Seu sucesso é proporcional à sua habilidade para esconder seus próprios mecanismos' (1981: 86); o poder não funciona negativamente pela dominação forçada dos que lhe são sujeitos, ele os incorpora e é produtivo no sentido de que os molda e reinstrumentaliza, para ajustá-los a suas necessidades. (FAIRCLOUGH, 2001, p. 75)

\footnotetext{
${ }^{3}$ Nesta citação, Fairclough faz referência a Foucault (1981).
} 
A hegemonia não se sustenta apenas com base na força, mas tem de dispor de processos sofisticados para apaziguar as tensões imanentes à distribuição desigual de poder. Um desses processos é a produção de sentidos, estando aí o embate na esfera discursiva. Assim, entende-se em ADC que a repetição de um discurso (forma particular de ver o mundo ou parte dele) em textos é sintoma do sucesso que a hegemonia alcança na manutenção do poder. Discursos, então, podem ser elaborados e empregados ideologicamente, sendo ideologia um conceito associado a processos de disseminação de uma representação particular do mundo como se fosse a única possível e legítima, o que pode resultar no efeito de naturalizar desigualdades. A esse respeito, Fairclough (2003) observa que os efeitos de sentido que mais interessam à ADC são, justamente, os efeitos ideológicos, sendo o desvelamento das articulações ideológicas que os textos podem promover um dos principais objetivos da pesquisa na área. Assim, pretende-se perturbar a estabilidade hegemônica, com intuito de contribuir para que mudanças ocorram. Isso faz da ADC um campo da ciência social crítica.

No caso do recorte de pesquisa aqui discutido, investigamos uma publicação que contribui para que a vulnerabilidade ligada ao empobrecimento seja percebida de forma reflexiva. É sabido que a mídia tem grande relevância social, por ser veículo, muitas vezes, para a propagação de discursos hegemônicos (PAIVA; BARBALHO, 2005; RICHARDSON, 2007), sendo um importante território de luta hegemônica e atuando ideologicamente, a serviço de determinados grupos da sociedade. A mídia tradicional opera mascarando as causas da situação de rua, colaborando para que essa realidade seja entendida como permanente e imutável (temos destacado isso em pesquisas anteriores, como em RESENDE, 2012, 2013, 2015, 2016; RESENDE; RAMALHO, 2013). Em contrapartida, a produção de street papers e de iniciativas como $O$ Trecheiro atua contraideologicamente, objetivando favorecer maior visibilidade para a complexidade da situação de rua e, assim, legitimar a luta da população em situação de rua (nossos trabalhos em ACOSTA; RESENDE, 2014a, 2015 chamam a atenção para isso).

Tendo isso em mente, defendemos a relevância do projeto de pesquisa integrado de que este artigo traz um recorte: investigou a representação midiática de uma realidade para a qual a sociedade parece querer fechar os olhos (PARDO ABRIL, 2008; PARDO, 2012; MONTECINO; ARANCIBIA, 2013). Na próxima seção, mostraremos 
um recorte analítico dos dados de $O$ Trecheiro que investigamos no projeto. $^{4}$

\section{Exercício analítico: análise discursiva crítica aplicada a $O$ Trecheiro}

As ferramentas básicas para uma análise discursiva crítica são as categorias analíticas, que não devem ser definidas a priori em um projeto de investigação, sendo necessário ter acesso aos dados que os textos (objeto central da investigação em ADC) oferecem para, então, poder identificar indutivamente as categorias analíticas que serão mais produtivas para a pesquisa. Para realizar as breves análises que apresentamos nesta seção, lançamos mão de algumas categorias em função dos recortes de dados que na sequência serão apresentados. As mais relevantes serão significado de palavra, intertextualidade e interdiscursividade, mas outras - transitividade, modalidade, metáfora - serão mobilizadas de maneira articulada a essas principais.

\subsection{A força da tradição e a via alternativa de $O$ Trecheiro: práticas discursivas}

A categoria significado de palavra foi selecionada, tendo como foco a oposição deflagrada por esse jornal a práticas jornalísticas tradicionais. Essa é uma categoria relacionada ao significado representacional, por ser a base para a construção de representações de mundo. O sistema lexical é parte do sistema semiótico prévio aos textos, e, portanto, o léxico é compartilhado e revela as maneiras como a sociedade que produziu funcionalmente seus usos regulares entende uma realidade. Apesar do compartilhamento social de modos de uso regulados do léxico, a agência do/a produtor/a de texto não é apagada; ao contrário, ela se mostra também na seleção lexical e na atribuição de significados elaborada nos textos, já que os sentidos das palavras são dependentes de escolhas de padrões de colocação, sendo também foco de disputas

\footnotetext{
${ }^{4}$ Para outras análises de $O$ Trecheiro, ver Acosta (2012), Acosta e Resende (2015, 2014a; 2014b); para análises de Aurora da Rua, ver G. Santos (2013); para análises de Boca de Rua, ver A. Santos (2013); para análises de Ocas, ver Acosta (2012), Acosta e Resende (2014b); para análises de Cais, ver Resende (2013), Resende e Marchese (2011), Resende e Alexandre (2010).
} 
discursivas. Essa escolha coocorre com a escolha (consciente ou não) de posicionamento político-ideológico em relação ao mundo representado. O jornal produzido pela Rede Rua para atender à necessidade de se criar um espaço no meio impresso para a divulgação, a difusão e o debate de questões relativas à comunidade de pessoas em situação de rua recebe o título $O$ Trecheiro. O nome 'trecheiro' não se encontra dicionarizado, mas é usado nas regiões Sul e Sudeste do Brasil para se referir a pessoas que têm uma vida nômade, não pertencendo a um determinado local, migrando e ocupando os espaços públicos (praças, baixos de pontes, viadutos, marquises etc.). O nome deriva de 'trecho', que se refere a um intervalo de duração definida ou, analogamente, a um espaço físico delimitado. ${ }^{5} \mathrm{O}$ fato de o 'trecheiro' ser aquele que ocupa/vive nos 'trechos' dos centros urbanos mostra uma maneira de entender a situação de rua sempre orientada no sentido da não pertença, da brevidade em um ou outro local, o que acaba reificando a situação na qual se encontram as pessoas às quais se aplica o termo "trecheiro".

No contexto estudado, porém, o termo ganha um caráter valorativo do "Povo da Rua" - parte do subtítulo do jornal: "Notícias do Povo da Rua". ${ }^{6}$ No espaço aberto por esse jornal, a rua é o foco, e com o termo 'trecheiro' coocorrem palavras de caráter valorativo, como "povo", que revela a união das pessoas que se encontram marginalizadas. Esse agrupamento de pessoas contra a situação de vulnerabilidade e suas consequências é, geralmente, mascarado pela grande mídia, que insiste em fragmentar o grupo em indivíduos, fragilizando ainda mais sua condição (RESENDE, 2015, 2016). Por outro lado, seria possível argumentar que "Povo da Rua" também pode ser interpretado como um epíteto que segrega: trata-se de um povo específico, ademais caracterizado por ser "da rua"? Na primeira interpretação, "povo" opera positivamente, unificando esse (grande) grupo populacional e colaborando, dessa maneira, para a construção simbólica de uma identidade coletiva, o que fortalece cada indivíduo que se identifique com essa causa - e, principalmente, chamando a atenção para o expressivo contingente populacional que se

\footnotetext{
${ }^{5}$ Trecho: s.m. Pequeno espaço de tempo ou lugar; intervalo. / Excerto, pequena passagem de uma obra literária ou musical. // loc. adv. A trecho ou a trechos, de tempo em tempo, de quando em quando. (vide Dicionário Aurélio versão online).

${ }^{6}$ Para uma análise multimodal detalhada da apresentação verbo-imagética do título do jornal, ver Acosta e Resende (2015).
} 
encontra nessa situação. Na segunda interpretação possível, por outro lado, pode-se sustentar que a expressão opera exclusão desse mesmo contingente populacional em relação ao povo brasileiro de modo mais amplo e que a fixação dessa parcela da população, no qualificador "da Rua", pode ter efeito de reificação, assim como se observa para "morador de rua", por exemplo. Talvez essa tensão interpretativa tenha sido a causa da mudança do subtítulo do jornal, a partir de 2016, para "Jornalismo a serviço da população em situação de rua".

No cerne dessas escolhas está um posicionamento consciente por parte dos/as editores/as do jornal, o que é expresso de forma mais direta principalmente no espaço dos editoriais. A consciência sobre o ato linguístico não é expressa apenas pelos/as editores/as do jornal, mas também por seus/suas leitores/as. A reflexão acerca do léxico ocorre, por exemplo, na carta de uma leitora que se encontrava em situação vulnerável, publicada na capa da edição de janeiro/fevereiro de 2010 do jornal. A seguir reproduzimos a carta integralmente:

\section{Prezados senhores da redação do Jornal}

Ao O Trecheiro

Eu estou me sentindo muito humilhada por ser chamada de moradora de rua. Eu trabalho na Coorpel e, por isso, os assistentes de saúde só chama nós de moradores de rua. Eu acho que moradores de rua são aqueles que dome na rua, passam dia e noite nas ruas. Quem trabalha num serviço que é pior que trabalhar na roça debaixo do sol ou da chuva, e tem um teto parra passar a noite, não podem ser chamados assim. Quero saber por que nós temos que carregar essa humilhação enquanto estivermos em atividade na Coorpel?

Eu estou no hotel social e não pode nem mudar o endereço porque senão perdemos o direito assistencial da saúde da Casa da Misericórdia. Que absurdo!!!! Quero alugar um quartinho abençoado, mas o que adianta, para levar essa humilhação, é quem está de acordo com isso. Melhor continuar como estou. Assinado: Maria, agradece! (sic)

Em sua carta, a senhora Maria compartilha um pouco de sua experiência laboral como catadora de materiais recicláveis e demonstra indignação por ser chamada de "moradora de rua" pelos "assistentes de saúde". No plano textual, sua revolta contra essa classificação constrói-se 
em "Eu estou me sentindo muito humilhada", em que o processo mental (nesse caso reflexivo) 'sentir-se' representa, no discurso, a experiência do mundo interior da autora ("muito humilhada"), e na justaposição entre "não podem ser chamados assim" e "Quero saber por que nós temos que carregar essa humilhação", em que se refuta a classificação por meio do uso dos modalizadores e novamente pela escolha lexical ("humilhação").

A recorrência do campo semântico da humilhação para representar o sentimento decorrente da classificação como "moradora de rua" revela o forte teor pejorativo da expressão e suas consequências psicológicas sobre as pessoas, expressas no sentimento que descreve essa leitora. Por outro lado, sua indignação se faz ver no ato de argumentar que de nada adianta trabalhar duro para tentar sair da rua se a sociedade não a acolhe nem, muito menos, reconhece seu esforço. Isso revela o caráter condenatório de uma expressão como "morador de rua", segundo a qual a pessoa é "de rua" e não está na rua: a condição de vulnerabilidade é naturalizada a ponto de ser tomada como uma característica inerente da pessoa (RESENDE, 2008). Tal representação opera dissimulando a incoerência do sistema em que coexistem, por exemplo, tecnologias das mais variadas e grupos de pessoas que não têm acesso sequer a seus direitos mínimos. Ao não aceitar essa pecha, essa condenação, a leitora do jornal nos mostra como está contido no elemento linguístico todo um dramático panorama social.

Cabe, no entanto, frisar que essa escolha lexical pode não ser consciente, pois, muitas vezes, reproduzem-se maneiras de representar o mundo atreladas a determinados grupos hegemônicos, em razão da pressão discursiva que esses grupos exercem sobre o conjunto da sociedade. Uma das principais estratégias ideológicas é a disseminação de discursos, fazendo com que estes colonizem variados tipos de texto, sem que haja reflexividade a esse respeito. Essa reprodução é, muitas vezes, feita de maneira não intencional, pela assimilação do conjunto de saberes e formas que a hegemonia promove.

Ainda sobre isso, podemos observar que, nos jornais e revistas da mídia de grande circulação, a realidade das pessoas em situação de rua é mascarada na forma de preconceitos que responsabilizam a pessoa e ocultam as causas sociais da situação de rua (RESENDE, 2016, 2015). Retomamos as palavras de Benevenuto (2006, p. 2), que resume o que é a grande mídia e como ela atua: 
Por comunicação dominante, resumidamente, entende-se o fenômeno comunicacional que ocorre através de meios de comunicação de massa legalmente e tradicionalmente constituídos, reconhecidos pela audiência (público) como tal. A esse raciocínio, Madrid adiciona que são meios que "se converteram nos instrumentos mais eficientes para se obter cotidianamente, de forma massiva e quase intangível, a articulação da base material da formação histórica com a sua superestrutura de organização e regulação."

Benevenuto evidencia o poder da grande mídia, e nós, pesquisadoras e pesquisadores em ADC, podemos acrescentar que esse poder se sustenta, em grande medida, - ao lado, obviamente, do poder econômico, que se converte em poder político, que, por sua vez, converte-se em poder econômico e, assim, sucessivamente, como enfatizou Bourdieu, 2011, - pela linguagem elaborada, com o alto grau de sofisticação técnica que as revistas e jornais conseguem desenvolver em sua produção. Nessa mesma direção, Pardo Abril (2008) analisa a imprensa colombiana, em uma análise que poderia facilmente ser transposta a nossa realidade:

O fenômeno da pobreza é proposto na imprensa como imutável, quando se atribui a ele um caráter histórico e permanente, articulado ao fato da evidente concentração de riqueza em um setor minoritário do país [...]. A prática discursiva na imprensa colombiano aponta o compromisso que se consolidou entre interesses econômicos e políticos, e uma indústria da informação associada a esses interesses. Este fenômeno é evidente na Colômbia, pois no país o único jornal de circulação nacional, em papel e digital, pertence a uma família com laços políticos e associada a grupos econômicos multinacionais. (PARDO ABRIL, 2008, p. 419)

Nesse trecho, a pesquisadora observa que a situação de vulnerabilidade econômica é representada como algo imutável, histórico e permanente, e consequentemente natural. Assim, a grande mídia opera tendo como efeito um apagamento de responsabilidades pela acumulação de renda e pela apartação social, ao mesmo tempo que enfatiza responsabilidades individuais das pessoas em situações vulneráveis. Pardo Abril também observa a suspeita 'coincidência' de 
os veículos mais importantes da mídia tradicional colombiana serem de propriedade de uma família que está ligada tanto ao poder econômico quanto ao político, tendo evidentemente interesse em mascarar certas facetas da realidade nacional. No Brasil, o controle midiático de poucos grupos ligados a algumas poucas famílias ${ }^{7}$ e a compra de veículos de mídia por políticos também são fatos conhecidos.

Sobre concentração midiática, e atentando para alguns de seus efeitos sociais, Pires (2013, s/p) enfatiza que:

A concentração da comunicação no Brasil é aterradora. Não fosse isso por si só péssimo, essa mídia empresarial ainda dita, à sua maneira mercadológica, padrões culturais e de comportamento atrelados à lógica do consumismo e umbilicalmente ligados ao interesse maior de manter o status quo. Ao seu modo, a mídia empresarial, controlada por essas poucas famiglias de magnatas, mantém o estado das coisas do jeitinho que está: privilégios socioeconômicos para as suas castas e seus bajuladores e ignorância cultural e miséria para o restante do povo - no meio desse fosso de disparidade, repousa o "retrato comum" da classe média brasileira, alheia aos problemas sociais, mas preocupada em comprar o novo modelo de iPhone que acabou de ser lançado.

Na contramão disso, aparecem veículos de mídia alternativa como uma via para a expressão de outras vozes e interesses, entre os quais estão os street papers abordados no projeto integrado de pesquisa de que aqui fazemos pequeno recorte. Nesse contexto, O Trecheiro apresenta

\footnotetext{
${ }^{7}$ De acordo com o Observatório do Direito à Comunicação, "Dos anos de 1990 até recentemente, o que se configurou de maneira acentuada foi o movimento ascendente de concentração da mídia nacional e a consequente redução drástica de grupos (em sua maioria, empresas familiares) no controle dos principais veículos de comunicação do país. Algo em torno de nove grupos familiares controlavam a grande mídia no decorrer da última década [...]. Atualmente, o número de mandatários da grande mídia de abrangência nacional encolheu para seis grupos apenas. Isso porque foram retiradas da lista as tradicionais famílias Bloch, Levy, Nascimento Brito e Mesquita, que não exercem mais controle direto sobre seus veículos de comunicação. Civita, Marinho, Frias, Saad e Abravanel [...] são os clãs que comandam o oligopólio midiático no Brasil." Disponível em: <http://www.direitoacomunicacao.org.br/index2.php?option=com docman\&task $=$ doc_view\&gid=342\&Itemid=99999999> . Acesso em: maio 2015.
} 
diferentes maneiras de tratar a situação de rua e a vulnerabilidade, posicionando-se ao lado de grupos sociais empobrecidos e, para além disso, propondo soluções para que, pelo menos, seus direitos básicos sejam garantidos.

\subsection{Intertextualidade: entre ação e representação}

A discussão de Bakhtin (2002 [1953]) sobre dialogismo, segundo a qual qualquer texto encontra-se inevitavelmente inserido em uma cadeia dialógica com os textos que vieram antes dele e com aqueles que virão depois, foi basilar para o desenvolvimento dos estudos do discurso, especialmente para a formulação de teorias do funcionamento social da linguagem, e permanece influente em várias vertentes de análise de discurso, inclusive na versão de ADC com que lidamos na Universidade de Brasília (VIEIRA; RESENDE, 2016).

No sentido mais evidente, a intertextualidade refere-se a partes de textos articuladas em outros textos, ou seja, às citações (FAIRCLOUGH, 2003). Mas existem vários modos de se construir relações intertextuais, e eles nos dão indícios das práticas que estão na origem dos textos, pois caracterizam formas de agir e se posicionar: ao dar maior ou menor espaço a uma voz, mais ou menos explicitamente, o/a autor/a do texto demonstra qual o seu alinhamento e qual a importância que atribui às vozes que atualiza em seu ato linguístico. Isso localiza a intertextualidade como característica do significado acional da linguagem, pois, ao selecionar fragmentos de outros textos e incorporá-los ao seu, o/a autor/a age efetivamente sobre o mundo.

Uma das grandes questões que se impõem à mídia alternativa é a efetiva participação das pessoas às quais seus produtos se destinam. Essa questão é relevante para todos os movimentos em que intelectuais ou quaisquer pessoas que tenham maior poder simbólico tentam alinhar-se às causas de pessoas que encontram usurpados seus direitos mínimos. O mesmo paradoxo que põe em xeque a verossimilhança das obras de Graciliano Ramos, por exemplo, cria entraves para os jornais de rua, na produção das notícias e da informação sobre a situação que pretendem abordar. Seja na ficção, seja no jornalismo, corre-se o risco de se apresentarem vozes parcialmente mimetizadas, ouvindo-se delas apenas ecos.

Os textos de $O$ Trecheiro negociam espaço com vozes em situação de rua, o que deixa ver o grau de engajamento dos/das editores/as com a questão e sua preocupação ética. As vozes de pessoas em situação de 
rua presentes nos textos do jornal são, muitas vezes (veja outras formas de materialização dessa polifonia na seção seguinte), trechos de fala articulados em citações diretas ou rearticulados por meio de citações indiretas, entremeados nos textos dos/as editores/as e colaboradores/as do jornal, o que caracteriza materialização convencional do potencial genérico para textos jornalísticos. A inovação, nesses casos, é que essas vozes vêm sempre acompanhadas de trajetórias resumidas das pessoas. Observa-se essa estrutura de articulação intertextual no corpus aqui considerado, como no seguinte excerto, retirado da edição de novembro de 2010:

W. S. Machado, 28 anos, está morando na rua por causa de drogas, recebe pensão por invalidez, mas encaminha todo o dinheiro para esposa e filhos. "Já tentei fazer um tratamento, mas a droga é uma doença e não tenho mais o que fazer", declarou Machado. Para ele essas ações [de derrubada de "casas improvisadas das pessoas em situação de rua" e recolhimento de "todos os objetos que estivessem no espaço", segundo a mesma matéria] são abusivas e subumanas. "Mesmo usando uma calçada, a gente tem o nosso direito de, no mínimo, um lar", completou.

Nesse exemplo, a voz autoral, de Alderón Costa, então editor do jornal, é uma voz- guia que articula e atualiza as falas de outras pessoas. Nos textos analisados, esse tipo de articulação acontece tanto para as vozes de pessoas em situação de rua quanto para as vozes de pessoas que de alguma forma trabalham com essa realidade (religiosos/as, assistentes sociais, membros do Movimento Nacional da População em Situação de Rua, MNPR, promotores/as de justiça, entre outros/as), o que pode ser identificado com o que Fairclough (2003) classifica como um cenário de abertura para a diferença.

Nos textos analisados na pesquisa da qual este artigo apresenta um brevíssimo recorte, a intertextualidade articula-se intrinsecamente com a representação de atores sociais (van Leeuwen, 2008), o que é mais uma característica convencional de gêneros jornalísticos como a notícia. Essa característica possibilita uma análise que combine esses dois aspectos textuais (como nas análises apresentadas em Resende, 2013). Apesar de essa segunda categoria analítica ser relacionada ao significado representacional (em que o texto opera representando as coisas do mundo), sabemos que os diferentes significados do discurso propostos em 
Fairclough (2003) não devem ser tomados como separados; ao contrário, são construídos dialeticamente. Assim, pesquisas em ADC não somente devem categorizar visando sistematizar suas análises, mas devem também poder articular diferentes significados, bem como diferentes categorias nas análises, aproximando, dessa maneira, o modelo teórico do objeto real que pretendem descrever.

Essa proximidade entre representação e intertextualidade também foi evidenciada em Resende e Ramalho (2006, p. 67), quando abordam a agência no texto e observam que a "representação no discurso não é uma mera questão gramatical, ao contrário, é um processo ideológico cuja relevância deve ser considerada". Isso pode levar à conclusão de que esse deva ser um ponto de contato regular entre os diferentes significados, a representação explicitando a ação.

Diferentemente de jornais da chamada grande mídia, em $O$ Trecheiro as pessoas em situação de rua são nomeadas, suas histórias de vida e as circunstâncias que as levaram a viver nas ruas são explicitadas. Isso indica um esforço representacional de inclusão no texto pela representação dos traços humanos dos atores sociais - o que, por absurdo que possa parecer, não é recorrente na mídia tradicional (RESENDE, 2015) - e um reconhecimento de suas narrativas, do que decorre o vínculo da representação textual a uma lógica explanatória, nos termos de Fairclough (2003), já que relações causais são reconhecidas. Isso pode favorecer outro olhar sobre os mesmos problemas e, para além disso, pode servir de base para que pessoas em situação de rua se vejam representadas e possam, a partir daí, (re)formular suas identidades.

\subsection{Mudança genérica e interdiscursividade}

Como exemplo de mídia alternativa, $O$ Trecheiro apresenta criatividade no que concerne à maneira como, nele, são materializados gêneros jornalísticos. O suporte é bastante dinâmico, no sentido de que há adaptações evidentes para melhor atender à população em situação de rua. Com base na análise dos volumes de agosto de 2010 a janeiro/fevereiro de 2011, foi possível verificar que houve mudanças na realização estrutural do jornal, tendo sido criadas, no decurso desse curto período, três novas colunas: "Ruagenda" (presente nos volumes de dezembro e janeiro/fevereiro), "Vida no Trecho" (presente em todos os volumes analisados, mas não em volumes anteriores a que também tivemos acesso) e "Direto do Trecho" (presente nos volumes de agosto 
a novembro de 2010). Além disso, nos moldes do "Vida no Trecho", na capa da edição de janeiro/fevereiro, aparece a transcrição e a imagem de uma carta enviada a $O$ Trecheiro por uma pessoa em situação de rua, como vimos neste mesmo artigo.

Essa reestruturação do jornal pode ter sido orientada pelo objetivo de contemplar efetivamente as pessoas em situação de rua na publicação que a elas se destina. Isso evidenciaria o caráter inclusivo dessa iniciativa, pois não se trata apenas de ecos rearticulados de vozes (vide discussão anterior sobre intertextualidade), mas da criação de um espaço fixo, a ser habitado por histórias pessoais e visões de mundo particulares. A coluna "Vida no Trecho" é um espaço aberto para a contribuição por meio de cartas ou depoimentos, retomados pelo editor Alderón Costa, de pessoas em situação de rua, ou com trajetória de rua, nas quais elas narram um pouco de sua história. A seção "Direto do Trecho" realiza o gênero coluna de opinião, e os textos são sempre assinados por Salvador d'acolá, que se encontra em situação de rua. Essa coluna é muito particular, pois a qualidade dos textos de seu autor deixa ver a capacidade reflexiva da população em situação de rua, o que por um lado agrega-lhe mais valor e, por outro, permite que outras pessoas em situação de rua tenham um reforço de sua identidade, sentindo-se estimuladas, por exemplo, a também escrever suas reflexões.

Nesses textos assinados por pessoas em situação de rua, podemos acessar os discursos (modos de representação particulares) mais frequentes no jornal, de forma geral. Desses discursos, vale observar mais atentamente o discurso da violência, o discurso do trabalho e o discurso da esperança. Os discursos são formas particulares de representar o mundo ou parte dele; desse modo, observar quais são os discursos presentes e como eles são articulados em textos oferece fortes indícios de como as práticas representadas são compreendidas. Segundo Resende e Ramalho (2006), a articulação da diferença, que deve ser observada ao se explorar a intertextualidade, também importa na análise de interdiscursividade.

$\mathrm{O}$ aspecto interdiscursivo dos textos presentes no suporte $O$ Trecheiro apresenta um direcionamento contrário ao da mídia tradicional na representação da situação de rua, por desenvolver maneiras diferentes de abordagem de questões relativas à realidade da rua: dos discursos mais comuns (sobre violência, trabalho e esperança), pode-se dizer que a forma como são tratados esses aspectos do mundo é totalmente outra, 
e isso mostra como um mesmo aspecto do mundo pode ser representado de maneiras muito diversas (podemos comparar às representações discursivas da violência associada à pobreza, por exemplo, nos dados de Pardo Abril, 2008, ou de Resende, 2012).

A temática da violência associada à vulnerabilidade social, quando tratada pela chamada grande mídia, via de regra responsabiliza as pessoas em situação de rua, reificando-as. No caso de $O$ Trecheiro, é possível entender a violência sob outra perspectiva: a das pessoas em situação de rua. No jornal, são representados dois tipos básicos de violência: a violência institucionalizada e a violência da sociedade civil.

A seguir, podemos ler um relato de violência institucionalizada, em um excerto de um texto publicado na coluna "Direto do Trecho", do volume de setembro/outubro de 2010, sobre o sistema assistencial de São Paulo:

A pedagogia da humilhação já começa como uma forma de triagem. Apenas somente quem realmente precisa aceita o mau tratamento destes funcionários oferecidos em parcerias onde quem mais precisa é o menos fortalecido, mais fragilizado e vulnerável socialmente falando. Nunca peguei cadeia, mas o albergue parece uma extensão do sistema penitenciário.

Salvador d'acolá descreve, nesse texto de sua coluna mensal, a situação enfrentada por quem busca abrigo nos albergues da capital paulista. Ele constrói a expressão "pedagogia da humilhação", que, segundo ele, representa a prática social que orienta as ações dos/as assistentes desses albergues. Nessa lexia, por analogia, depreende-se que, ao contrário da proposta freiriana, o resultado da dinâmica social estabelecida nesse contexto aprisiona os/as albergados/as em um ciclo de violência com base na humilhação. A violência representada nesse caso é a violência institucionalizada da assistência que não assiste. A crítica institucional também se deixa ver na avaliação depreendida da curiosa estrutura modal em "Apenas somente quem realmente precisa", enfatizando o abrigo como última opção.

A seguir, reproduzimos parte de uma carta endereçada a $O$ Trecheiro, publicada na seção "Vida no Trecho", também no volume de setembro/outubro de 2010. Na carta, Carlos Ferreira de Lima relata seu esforço para sair das ruas, o drama que enfrentou no albergue em que 
esteve durante alguns meses e a dificuldade encontrada no trabalho como ambulante, na venda de imagens de santos. No exemplo, a violência institucional representada é a que parte das forças da ordem policial:

A Prefeitura me tomou quase $\mathrm{R} \$ 200,00$ de imagens, ainda me machucaram ao me segurarem por trás como se eu fosse bandido. Tá certo, meus santos não têm nota fiscal, mas será que não tenho o direito de sobre-viver? E daí? Que lei é essa?

Nesse trecho da carta, o autor põe em xeque a forma como o aparato repressor o percebe, o que se materializa textualmente na negativa pressuposta em "como se eu fosse bandido", por meio da qual afirma sua identidade como trabalhador. Ao mesmo tempo, questiona a "lei" que recai sobre ele, potencialmente lançando-o de volta às ruas, por impedir-lhe o trabalho informal que lhe garante "sobre-viver". Assim, além de rejeitar a identidade marginalizada que lhe é imposta, ele constrói uma alteridade violenta para o Estado, o que se realiza de três formas: pela escolha lexical por "tomou", para representar a ação da prefeitura; pela representação da ação policial por meio de processo material que denota ação violenta e pressupõe avaliação negativa ("machucaram"), ainda enfatizado na circunstância também violenta ("ao me segurarem por trás"); pelo questionamento do aparato legal que legitima esse tipo de ação da prefeitura e da polícia, especialmente nas repetidas estruturas interrogativas ("será que não tenho o direito de sobre-viver? E daí? Que lei é essa?") e no jogo de palavra que resulta da partição em "sobre-viver".

Outro tipo de violência representado no corpus é a violência da sociedade civil. Vejamos o exemplo de um trecho da matéria de capa do volume de agosto de 2010, intitulada "Em Curitiba, 'nem olham na sua cara"":

Os curitibanos nem olham na sua cara $[\ldots]$. Você não é considerado pelo próprio conterrâneo como um ser humano. Você abre a boca para pedir um pão, não te olham nem na cara. Eu acho que eles pensam que quem está na rua é lixo.

Trata-se aqui de representação da violência simbólica à qual pessoas em situação de rua são constantemente expostas. Nesse trecho de fala representada, o jovem Michael Ferreira, também representado imageticamente na matéria de capa (uma análise imagética está disponível 
em Acosta e Resende, 2015), usa construções negativas (com “nem”, "não" e novamente "não") em que o traço de humanidade das pessoas em situação de rua é apagado na percepção (representada) daqueles/as que não se encontram nas mesmas condições. Novamente, nesse excerto representa-se a insatisfação pela forma como se é tratado/percebido pelos/ as demais, o que se reforça pela repetição ("nem olham na sua cara" e "não te olham nem na cara"). Considerando análises anteriores de textos publicados em meios tradicionais de comunicação social, podemos dizer que nesse trecho recusa-se a recorrente e ultrajante associação entre pessoas em situação de rua e lixo, como no texto da Folha de S. Paulo analisado em Resende (2015). Aqui, em lugar das insidiosas associações indiretas que foram observadas na Folha de S. Paulo, abre-se espaço para a denúncia direta da desumanização: "Eu acho que eles pensam que quem está na rua é lixo".

Assim, a violência da sociedade contra os/as que vivem nas ruas é denunciada pelo jornal, que põe em pauta também as inúmeras, não investigadas e impunes mortes de pessoas em situação de rua, seja pela ação assustadoramente frequente (lembremos os recentes casos de Goiânia em 2013) de grupos de extermínio, seja pelas condições precárias de vida. Isso é evidenciado no editorial do volume de dezembro de 2010, em que Alderón Costa afirma que:

O sistema está determinado a matar. De imediato: pode ser à bala ou a paulada. Ou a médio prazo: por inanição ou cansaço. É só escolher! A esperança é que novos atores comecem a perceber a violência desse sistema que vem arrastando pessoas para esta situação.

Novamente, encontramos no corpus resistência a ideias hegemônicas, como a de inevitabilidade da desigualdade social. No trecho inicial do excerto destacado, "O sistema está determinado a matar", a estrutura social é apresentada, por meio de personificação (van LEEUWEN, 2008), como voluntária e construída. Dessa maneira, $O$ Trecheiro representa a violência como sendo inerente/resultante do sistema, ao mesmo tempo que mostra a percepção da realidade, sob esse prisma, por parte de atores sociais, e sua consequente ação individual/ coletiva, como a "esperança" para a resolução do problema. O jornal se opõe à maneira como tradicionalmente o tema da violência é tratado nos meios de comunicação social (ver, por exemplo, a análise de Resende e Santos, 2012, de texto publicado no jornal $A$ Tarde). 
Além da violência, o jornal $O$ Trecheiro também aborda frequentemente a temática do trabalho. $\mathrm{O}$ trabalho é representado como forma de sobreviver, como forma de sair das ruas e, principalmente, como forma de conquistar reconhecimento social que afaste a sombra de humilhação em tantos textos de nosso corpus denunciada. Vejamos um exemplo extraído da matéria "Pesquisa em SP revela perfil e expectativas sobre trabalho", publicada em novembro de 2010 e assinada por Maria Carolina Ferro:

Além dessas questões ["aspectos fundamentais para pensar políticas públicas de trabalho e geração de renda": oferta de cursos profissionalizantes, encaminhamento a vagas de trabalho, acompanhamento psicossocial], a intersetorialidade das políticas públicas foi destacada como fundamental, isto é, que as políticas de trabalho estejam articuladas com as políticas de Assistência Social, Saúde, Educação e Habitação. Somente com políticas articuladas será possível a "saída das ruas" e reinserção no mercado de trabalho.

Segundo revelou a pesquisa mencionada na matéria, $90 \%$ das pessoas que se encontram em situação de rua trabalham regularmente. Assim, as pessoas que estão nas ruas são, em sua expressiva maioria, trabalhadoras, mas que se encontram em condições vulneráveis, com trabalho precário e sem qualquer garantia. Conforme o trecho da matéria que destacamos, políticas públicas intersetoriais são necessárias para que isso se realize, o que se texturiza pelo adjetivo "fundamental" e pelo recurso coesivo "Somente com" ligado a "será possível". Assim, as políticas públicas intersetoriais, como as preconizadas na Política Nacional para Inclusão da População em Situação de Rua (BRASIL, 2009), são representadas num horizonte de possibilidades ("será possível 'a saída das ruas"'), e avaliadas como indispensáveis para a superação da situação de rua.

Essa questão está intimamente ligada ao discurso da esperança. Esse discurso figura principalmente nos textos em que se podem ler narrativas de pessoas que conseguiram superar a situação de rua ou que estão numa via ascendente, alcançando sucessos nessa direção. A coluna "Vida no Trecho", de janeiro/fevereiro de 2011, intitula-se "Do trecho para Rua Oscar Freire", e sobre o título da matéria não nos deve escapar a texturização da cidade como espaço de segregação. Nesse texto, assinado 
por Alderón Costa, Marcelo Leite S. de Matos conta de sua felicidade ao ver os trabalhos que ele e sua esposa, Jaqueline Pereira, realizaram, no curso de fotografia do Instituto Brasis, expostos em uma galeria na rua Oscar Freire, uma rua dos jardins, região nobre de São Paulo. Ao final de sua narrativa, ele diz:

Agora o pai dele [Athos Daniel Pereira Leite, filho do casal, à época com três meses] vai estudar, se formar, e ele vai ter muito orgulho do pai. Não vou precisar fazer nenhuma coisa errada [referência à experiência anterior com drogadição, mencionada no texto].

O emprego do futuro composto orienta o efeito consecutivo das ações projetadas, em que Marcelo Leite encadeia “estudar", "formar-se" e "ter orgulho". Nessa construção, articula-se o discurso da esperança, nesse caso fortemente associado a um 'futuro melhor' para a família recém-constituída, e ao afastamento em relação a "coisa errada", o que é assumido como passado pressuposto no trecho de fala, recuperável no cotexto, e relacionado à situação de rua.

Em trecho anterior do mesmo texto, outra instância de discurso direto articulando a voz de Marcelo Leite retoma a desumanidade que vimos em excertos anteriores: "Eu sou gente. Estão achando que eu não sou mais gente, mas ainda eu sou gente". Assim como o jovem Michael Ferreira, de Curitiba, também Marcelo Leite denuncia a percepção social desumanizante. Da mesma maneira, a fala de Maria Lúcia Santos Pereira, de Salvador, coordenadora do Movimento Nacional da População em Situação de Rua (MNPR), retoma a questão, em texto assinado por ela e publicado no mesmo volume de O Trecheiro:

Durante muitos anos da minha vida, senti o desprezo e o descaso de uma sociedade que se dizia democrática. Ao entrar de cabeça no Movimento Nacional da População de Rua, de uma certa forma, foi um grito de liberdade e do desejo de ver um mundo melhor. Vontade de me sentir humana de novo, pois as ruas tiram toda a nossa dignidade e identidade. Em 2009, tive o prazer de sentar perto do presidente Luiz Inácio Lula da Silva e vê-lo assinar o Decreto das Políticas Públicas da População de Rua que, a meu ver, é nossa carta de alforria, pois éramos escravos do descaso e da discriminação da sociedade. Num momento 
pude ver de perto o rosto de um homem que havia olhado para o nosso sofrimento, que nos possibilitou sair da invisibilidade rumo ao protagonismo.

O texto reproduz discurso proferido por Maria Lúcia Santos Pereira em encontro com o já ex-presidente Luiz Inácio Lula da Silva e a então presidenta Dilma Rousseff, no $8^{\circ}$ Encontro de Natal da População em Situação de Rua, realizado em São Paulo, em 23 de dezembro de 2010. Esse texto, ao mesmo tempo que denuncia a desumanização ("Vontade de me sentir humana de novo"), representando negativamente a sociedade brasileira ("o desprezo e o descaso de uma sociedade que se dizia democrática", "éramos escravos do descaso e da discriminação da sociedade"), articula o discurso da esperança, celebrando a organização social do MNPR ("grito de liberdade e do desejo de ver um mundo melhor") e a Política Nacional para Inclusão da População em Situação de Rua ("carta de alforria"), por meio da metáfora de abolição. Nas relações de sentido estabelecidas no excerto, a autora sugere que a trajetória "da invisibilidade rumo ao protagonismo" é possível se as pessoas em situação de rua tiverem reconhecida sua "dignidade", para reconstruir sua "identidade" como atores coletivos organizados em movimento social.

Nos textos que vimos, a narrativa jornalística opera lançando luz sobre as vidas de pessoas que nos contam de suas angústias e sucessos, mostrando que são capazes e organizadas e que, assim como todas as pessoas, desejam ter uma vida plena de direitos: casa, lar, família, trabalho, reconhecimento, dignidade. São pessoas iguais e que deveriam ser, de fato, iguais. Por isso é importante evidenciar suas trajetórias, por meio de suas próprias vozes. Trata-se de contar histórias que não costumamos ouvir, por vozes que não encontram espaço nas tantas páginas dos jornais da chamada grande mídia (seria mais adequado 'mídia grande'), mas que nesse jornal de apenas quatro páginas mensais (ou às vezes bimensais) podem texturizar-se.

\section{Considerações finais}

Em textos constroem-se maneiras particulares de ver/entender o mundo, reiterando discursos ideológicos ou, na contramão, tentando superá-los. As maneiras como tradicionalmente são representadas pessoas em situação de rua na 'mídia grande' fazem parte de um conjunto de ações discursivas com efeito potencial de perpetuação de sistemas de 
oposição entre pessoas ou grupos de pessoas em polos de carência e acumulação; de negação de acesso aos direitos básicos, de um lado, e de 'direitos prioritários', de outro. Resistindo a discursos preconceituosos e aviltantes sobre a situação de rua, tão frequentes nos veículos tradicionais da comunicação social, $O$ Trecheiro propõe aos/às seus/suas leitores/as outros parâmetros para compreender a situação de rua, suas causas e consequências.

A inclusão de vozes de pessoas em situação de rua nos textos do jornal abre espaço para sua autorrepresentação, o que possibilita a materialização de narrativas outras, por outros prismas experienciais. Nesse espaço, leitores/as em situação de rua, público preferencial dessa iniciativa, podem se ver representados/as, podem refletir sobre as circunstâncias sociais que os/as levaram a estar nessa condição. E, assim, podem construir modos alternativos de identificação, com base em outros modos particulares de representação (discursos), para muito além daqueles que os/as desumanizam.

Os textos veiculados por $O$ Trecheiro criam uma porta simbólica que se abre da rua para dentro. Essa porta aberta é um convite ao diálogo com toda a sociedade. Ela estrutura um espaço no qual o debate sobre assuntos marginalizados pode ocorrer. Ao promover outra forma de retratar a realidade das ruas, na produção textual de informações em $O$ Trecheiro, a Rede Rua de Comunicação busca a mudança social por meio da mudança discursiva.

\section{Agradecimentos}

Agradecemos à FAP-DF pelo apoio à realização da pesquisa da qual se apresenta aqui um recorte, ao CNPq pela bolsa concedida ao projeto "Protagonismo face à inevitabilidade da violência: vozes da rua em Ocas" e em O Trecheiro", ao Centro de Estudos Sociais da Universidade de Coimbra, Portugal, pelo Prêmio Jovens Investigadores, conferido ao projeto "Publicações em língua portuguesa sobre / para a população em situação de rua: a revista Cais", e aos pareceristas anônimos que avaliaram este artigo e contribuíram com suas valiosas indicações e cuidadosa revisão. 


\section{Referências}

ACOSTA, M. P. T. Protagonismo face à inevitabilidade: vozes da rua em Ocas e em $O$ Trecheiro - análise de discurso crítica. 2012. $232 \mathrm{f}$. Dissertação (Mestrado em Linguística) - Universidade de Brasília, Brasília, 2012.

ACOSTA, M. P. T.; RESENDE, V. M. Análise de discurso crítica: reflexões sobre a investigação discursiva em contextos de resistência. In: MARCHIORI, M. (Org.). Linguagem e discurso. São Paulo: Difusão, 2014a.

ACOSTA, M. P. T.; RESENDE, V. M. "Não deu no rádio, no jornal ou na televisão" - Análise discursiva crítica de textos do jornal $O$ Trecheiro. In: OTONNI, M. A.; LIMA, M. C. Discursos, identidades e letramentos - abordagens de análise de discurso crítica. São Paulo: Cortez, 2014b.

ACOSTA, M. P. T.; RESENDE, V. M. Mudança discursiva no jornal O Trecheiro. In: MOURA, D. O.; PEREIRA, F. H.; ARGHIRNI, Z. L. (Org.). Mudanças e permanências do jornalismo. Florianópolis: Insular, 2015.

BAKHTIN, M. Estética da criação verbal. São Paulo: Martins Fontes, 2002.

BENEVENUTO, Á. Jr. Para apreender o alternativo na comunicação contemporânea. UNIrevista, Unisinos, v. 1, n. 3, 2006.

BHASKAR, R. Societies. In: ARCHER, M. et al. (Org.). Critical realism. Essential readings. London; New York: Routledge, 1998. p. 206-257.

BOURDIEU, P. O poder simbólico. 5. ed. Rio de Janeiro: Bertrand Brasil, 2011.

BRASIL. Casa Civil da Presidência da República, Subchefia para Assuntos Jurídicos. Decreto n. 7.053 de 23 de dezembro de 2009. Institui a Política Nacional para a População em Situação de Rua e seu Comitê Intersetorial de Acompanhamento e Monitoramento. Diário Oficial da União, Poder Executivo, Brasília, DF, 24 dez. 2009. Disponível em: $<$ http://www.planalto.gov.br/ccivil 03/ Ato2007-2010/2009/Decreto/ D7053.htm>. Acesso em: 24 jan. 2017.

BUARQUE, C. O que é apartação: o apartheid social no Brasil. São Paulo: Brasiliense, 2003. 
CANCLINI, N. G. Consumidores e cidadãos: conflitos multiculturais da globalização. Trad. Maurício Santana Dias. Rio de Janeiro: UFRJ, 2006.

CHOULIARAKI, L.; FAIRCLOUGH, N. Discourse in late modernity. Edinburgh: University Press, 1999.

D'ANGELO, C. G. Procedimiento alternativo: método de análisis de discurso audiovisual. In: PARDO ABRIL, N. G. Discurso em la web: pobreza em Youtube. Bogotá: Universidad Nacional de Colombia, 2012. p.133-145.

DICIONÁRIO AURÉLIO versão on-line.

FAIRCLOUGH, N. Discurso e mudança social. Trad. Izabel Magalhães. Brasília: Editora Universidade de Brasília, 2001.

FAIRCLOUGH, N. Analysing discourse: textual analysis for social research. London: Routledge, 2003.

FAIRCLOUGH, N. Language and globalization. London: Routledge, 2006.

FAIRCLOUGH, N. Global capitalism and change in higher education: dialectics of language and practice, technology, ideology. In: BAAL CONFERENCE, 2007, Edinburg, Scotland. Proceedings... London: Scitsiugnil Press, 2008. p. 131-140.

FAIRCLOUGH, N. Critical discourse analysis. The critical study of language. Harlow: Longman, 2010.

FAIRCLOUGH, N.; JESSOP, B.; SAYER, A. Critical realism and semiosis. Journal of Critical Realism (incorporating Alethia), Taylor and Francis Online, v. 5, n. 1, p. 2-10, 2002.

FOUCAULT, M. A ordem do discurso. Trad. Laura Sampaio. 5. ed. São Paulo: Edições Loyola, 1999.

FOUCAULT, M. History of sexuality. Harmondsworth: Penguin Books, 1981. v. 1.

GRAMSCI, Antonio. Concepção dialética da história. Trad. Carlos N. Coutinho. Rio de Janeiro: Civilização Brasileira, 1995.

HALLIDAY, M. A. K. Introduction to functional grammar. London: Edward Arnold, 1985. 
INSP. International Network of Street Papers (Rede Internacional de Jornais de Rua). "Habitat.100 million homeless in world. Most are women and dependent children". Disponível em: <http://www.unhchr.ch/tbs/ doc.nsf/(symbol)/CESCR+General+comment+4.En?OpenDocument>. Acesso em: 29 jul. 2011.

KRESS, G.; van LEEUWEN, T. Reading images: the grammar of visual design. London; New York: Routledge, 1996.

GRAMSCI, A. Concepção dialética da história. Trad. C. N. Coutinho. Rio de Janeiro: Civilização Brasileira, 1995.

MAGALHÃES, I. Eu e tu. Brasília: Thesaurus, 2000.

MONTECINO, L.; ARANCIBIA, M. C. Representaciones discursivas en comentarios de blogs de ciberperiodicos chilenos. Cadernos de Linguagem e Sociedade, Brasília, UnB, v. 14, n. especial, p. 278-304, 2013. Disponível em: <http://periodicos.unb.br/index.php/les/article/ view/9072>. Acesso em: 24 jan. 2017.

O TRECHEIRO. Jornalismo a serviço da população em situação de rua. São Paulo. Volumes de agosto de 2010, setembro/outubro de 2010, novembro de 2010, dezembro de 2010 e janeiro/fevereiro de 2011.

PAIVA, R.; BARBALHO, A. (Org.). Comunicação e cultura das minorias. São Paulo: Paulus, 2005.

PARDO ABRIL, N. G. ¿Que nos dicen? ¿Que vemos? ¿Que és... pobreza? Bogotá: Universidad Nacional de Colômbia, 2008.

PARDO ABRIL, N. G. Aproximaciones al discurso crítico multimodal. In: CORACINI, M. J. (Org.). Identidades silenciadas e (in)visíveis. Campinas: Pontes, 2011. p. 149-178.

PARDO, M. L. Teoría y metodología de la investigación lingüística. Método sincrónico-diacrónico de análisis lingüístico de textos. Buenos Aires: Tersites, 2011.

PARDO, M. L. Asociación discursiva entre pobreza y delito. In: PARDO ABRIL, N. G. Discurso em la web: pobreza em Youtube. Bogotá: Universidad Nacional de Colombia, 2012. p. 270-293. 
PIRES, A. A concentração midiática e a negação da vida real. Observatório da Imprensa, São Paulo, edição 731, 29 jan. 2013. Disponível em: $<$ http://observatoriodaimprensa.com.br/feitos-desfeitas/_ed731_a concentracao_midiatica_e_a_negacao_da_vida_real/ $>$ Acesso em: $2 \overline{4}$ jan. 2017.

RAMALHO, V. C.; RESENDE, V. M. Análise de discurso (para a) crítica: o texto como material de pesquisa. Campinas: Pontes, 2011.

REDE RUA DE COMUNICAÇÃO. Disponível em: <http://www. rederua.org.br/index.php?option $=$ com_content\&task $=$ view\&id $=3 \&$ Ite mid=24> Acesso em: 10 mar. 2011.

RESENDE, V. M. Análise de discurso crítica e etnografia: o movimento nacional de meninos e meninas de rua, sua crise e o protagonismo juvenil. 2008. 332f. Tese (Doutorado em Linguística) - Universidade de Brasília, Brasília, 2008.

RESENDE, V. M. A revista Cais entre o protagonismo e o assistencialismo: uma análise discursiva crítica. Revista Crítica de Ciências Sociais, Coimbra, Universidade de Coimbra, v. 94, p. 21-40, 2011. Doi: 10.4000/ recs. 1490.

RESENDE, V. M. Representação discursiva de pessoas em situação de rua no "Caderno Brasília": naturalização e expurgo do outro. Linguagem em (Dis)Curso, Universidade do Sul de Santa Catarina, Tubarão, v. 12, n. 2, p. 439-465, 2012. Doi: http://dx.doi.org/10.1590/S151876322012000200004.

RESENDE, V. M. Media, sexual exploitation of children and the National Street Children's Movement in Brasília: an analysis of texts' social effects. Critical Discourse Studies, Londres, v. 10, n. 3, p. 263-274, 2013. Doi: http://dx.doi.org/10.1080/17405904.2013.791234.

RESENDE, V. M. A violação de direitos da população em situação de rua e a violência simbólica: representação discursiva no jornalismo on-line. Revista Latinoamericana de Estudios del Discurso, Bogotá, Asociación Latinoamericana de Estudios del Discurso, v. 1, p. 71-92, 2015.

RESENDE, V. M. Representação de pessoas em situação de rua no jornalismo on-line: quais são as vozes convocadas para falar sobre a situação de rua?. Revista de Estudos da Linguagem, Belo Horizonte, UFMG, v. 24, n. 3, p. 955-988, 2016. Doi: http://dx.doi. org/10.17851/2237-2083.24.3.955-988. 
RESENDE, V. M. Análise de discurso crítica: reflexões teóricas e epistemológicas quase excessivas de uma analista obstinada. In: RESENDE, V. M. (Org.). Análise de discurso crítica: outras perspectivas. Campinas: Pontes. [no prelo].

RESENDE, V. M; ALEXANDRE, M. F. Representação discursiva da pobreza extrema - análise discursiva critica de um testemunho publicado em editorial da revista Cais. Revista Latinoamericana de Estudios del Discurso, ALED: Associação Latino-Americana de Estudos do Discurso, V. 10, n. 2, p. 87-105, 2010.

RESENDE, V. M; MARCHESE, M. C. "São as pessoas pobrezitas de espírito que agudizam a pobreza dos pobres": análise discursiva crítica de testemunho publicado na revista Cais - o método sincrônico-diacrônico. Cadernos de Linguagem e Sociedade, Brasília, UnB, v.12, p.150-178, 2011.

RESENDE, V. M; RAMALHO, V. C. Análise de discurso crítica. São Paulo: Contexto, 2006.

RESENDE, V. M; RAMALHO, V. C. Inequality and representation: critical discourse analysis of news coverage about homelessness. In: PASCALE, C. M. (Org.). Social inequality \& the politics of representation: a global landscape. Washington: Sage, 2013. p. 21-34.

RESENDE, V. M.; SANTOS, A. A. A representação de pessoas em situação de rua quando vítimas de chacina: uma análise discursiva crítica. Revista Latinoamericana de Estudios del Discurso, ALED: Associação Latino-Americana de Estudos do Discurso, v. 12, n. 2, p. 81-102, 2012.

RICHARDSON, J. Analysing newspapers: an approach from critical discourse analysis. Hampshire: Palgrave, 2007. Doi: https://doi. org/10.1007/978-0-230-20968-8.

SANTOS, A. A. O jornal Boca de Rua - espaço de possibilidades para pessoas em situação de rua: uma reflexão discursiva crítica. 2013. 110f. Dissertação (Mestrado em Linguística) - Universidade de Brasília, Brasília, 2013.

SANTOS, G. P. O jornal Aurora da rua e o protagonismo na situação de rua: um estudo discursivo crítico. 2013. 203f. Dissertação (Mestrado em Linguística) - Universidade de Brasília, Brasília, 2013. 
Van LEEUWEN, T. Discourse and practice: new tools for critical discourse analysis. Oxford: Oxford University Press, 2008. Doi: https:// doi.org/10.1093/acprof:oso/9780195323306.001.0001.

VIEIRA, V. C.; RESENDE, V. M. Análise de discurso (para a) crítica: o texto como material de pesquisa. Campinas: Pontes, 2016. 